\section{Susceptibility loci for COPD}

\section{By Lauren Martz, Staff Writer}

A genomewide association study from GlaxoSmithKline plc and Duke University has identified two new susceptibility loci for COPD that might not only help assess disease risk, but also lead to new therapeutic targets. ${ }^{1}$ A much larger, long-term study is already underway to address whether the loci are indeed associated with disease and not simply with smoking dependence.

Chronic obstructive pulmonary disease (COPD) is primarily caused by smoking and involves restricted airflow to the lungs. Emphysema and chronic obstructive bronchitis are two common forms of the disease. However, not all smokers develop the disease, and studies suggest a genetic component is involved in smokers' risk of developing COPD. ${ }^{2}$

To date, deficiency of serpin peptidase inhibitor clade A member 1 (SERPINA1; ATT; A AT) due to the presence of a mutated version of its gene, known as the $\mathrm{Z}$ allele, is the only proven genetic risk factor for COPD. ${ }^{3}$ According to

\section{"There is still no clear indication as to whether the SNPs that have been identified are a marker for addiction or of COPD specifically."}

-Noor Kalsheker,

The University of Nottingham the researchers hope the association will be revealed to be significant in the ongoing ECLIPSE (Evaluation of COPD Longitudinally to Identify Predictive Surrogate End-points) study, which could validate HHIP as a previously unknown susceptibility factor.

Tim Higenbottam, director of corporate clinical development at Chiesi Farmaceutici S.p.A., told SciBX that if the loci are further validated, they could be used to diagnose COPD risk and to identify the mechanisms responsible for its pathogenesis.

Chiesi's Atimos, a pressured metered dose inhaler formulation of formoterol fumarate, is marketed for long-term treatment of asthma and COPD.

\section{Further validation}

In ECLIPSE, about 28,000 well-characterized patients and controls are being followed for up to 3 years to understand the molecular pathology the loci and their association with COPD.

Noor Kalsheker, professor of clinical chemistry at the Institute of Genetics of The University of Nottingham, said the larger trial is necessary because "most genomewide association studies require a minimum of 2,000 subjects."

According to Kalsheker, the problem with genomewide scans is that "very rare variants and SNPs in certain regions of the genome are not picked up very well. Rare variants in a gene that might confer very high risk probably won't be picked up despite the high density of the screens."

Pillai told SciBX that his team is thinking of doing a deep sequencing and genotyping study to Sreekumar Pillai, a geneticist at GSK, the variant is only present in $1-2 \%$ of patients.

In their paper in PLoS Genetics, Pillai and colleagues now report the identification of variants on chromosomes 4 and 15 that might affect a larger swath of patients.

In an initial genomewide association study involving $823 \mathrm{COPD}$ patients and 810 smoking controls, the 100 SNPs most highly associated with COPD were chosen for additional analysis. That set included variants on chromosome 15 that have been associated with lung cancer and peripheral arterial disease (PAD) in previous studies ${ }^{4}$ and a variant on chromosome 4 that has recently shown a genomewide significant association to lung function $\left(p<5 \times 10^{-8}\right)$. $^{5}$

In three additional cohorts comprising over 3,000 patients and controls, the researchers replicated the association of two polymorphisms at the locus on chromosome 15 for variants of cholinergic receptor, nicotine, $\alpha 3$ (CHRNA3) and CHRNA5, the CHRNA3/CHRNA5 locus.

The variants, rs8034191 and rs1051730, were significantly associated with COPD ( $p=1.48 \times 10^{-10}$ and $\mathrm{p}=5.74 \times 10^{-10}$, respectively). The team estimated that the $C$ allele of the rs 8034191 SNP could be present in about $12.2 \%$ of COPD patients.

The hedgehog interacting protein (HHIP) locus on chromosome 4 showed a nonsignificant association with COPD in the studies. But identify more genetic variants in the regions of interest, including highrisk SNPs that might be missed with a genomewide approach.

Takahiro Yoshikawa, senior lecturer of sports medicine at the Osaka City University Graduate School of Medicine and a medical doctor specializing in respiratory medicine, especially asthma and COPD, said it will be important to determine whether the findings vary among different ethnicities.

"It is likely that racial/ethnic background might affect the findings in a genetics study," he said. "In addition, the phenotype of COPD also seems to vary among countries. For example, patients with the bronchitis type are predominant in the U.K., whereas those with the emphysema type are predominant in Japan."

Both Yoshikawa and Kalsheker also wanted to see additional confirmation that the loci in the PLoS Genetics article are specifically linked to COPD and not to related conditions or phenotypes.

"There is still no clear indication as to whether the SNPs that have been identified are a marker for addiction or of COPD specifically," said Kalsheker.

Yoshikawa noted that some patients in the genomewide study had a history of bronchial asthma, including smoking asthma. "Before we use these specific loci for screening purposes, it is necessary to examine whether the susceptibility gene for COPD in the study is not overlapped 


\section{TARGETS \& MECHANISMS}

with that for asthma and is strictly associated with the COPD phenotype alone," he said.

Previous studies have linked the loci identified in the PLoS Genetics paper to the risk of lung cancer. ${ }^{4}$ Kalsheker said those studies raised the same question as to whether the relationship was actually to lung cancer and not just to nicotine addiction.

Pillai and his team did address the issue of smoking dependence in their paper.

"Several analytical methodologies were used to assess whether these loci were linked to smoking dependence. We used statistical analyses techniques to factor out the effect of smoking, and the association was still genomewide significant," he said.

Pillai added: "Though the CHRNA locus has been shown to be associated with smoking dependence, here weve shown that there is something more than smoking dependence going on, and this probably will relate to inflammation."

\section{Tests and targets}

If the three-year ECLIPSE study does confirm the PLoS Genetics findings, the path toward a COPD risk screen could be straightforward. In addition, the genes of interest might lead to the identification of new pathways and molecules that could be targeted to treat the disease.

"As far as a diagnostic, we don't need to do a lot of work because the association is very convincing," said Pillai. "If we need to use this information for screening the smokers for propensity to develop COPD, the results can be directly used to develop in vitro diagnostics."

"Once validated, these loci could provide a very powerful risk profile," said Kalsheker. "There is definitely a huge demand for COPD risk assessment methods, in part because the disease is often detected too late. Anything to help detect affected individuals earlier could have a great impact on public health."
Regarding therapeutics, Pillai said the next step is to better understand the biological role of the identified genes in COPD.

"For utilizing this knowledge in therapeutic interventions, we need to do functional studies including in vitro experiments to find the biological role of the genes in lung disease, followed by drug discovery efforts," he said. "We have already found that the CHRNA3/CHRNA5 gene is related to emphysema (destruction of the lung tissue), which is one of the mechanisms in COPD."

Pillai said the preliminary results show that $H H I P$ variants contribute to airway disease.

According to Pillai, the findings in the PLoS Genetics article have not been patented. Their licensing status is undisclosed.

Martz, L. SciBX 2(14); doi:10.1038/scibx.2009.563

Published online April 9, 2009

\section{REFERENCES}

1. Pillai, S. et al. PLoS Genet.; published online March 20, 2009; doi:10.1371/journal.pgen.1000421

Contact: David B. Goldstein, Duke University, Durham, N.C. e-mail: d.goldstein@duke.edu

Contact: Sreekumar G. Pillai, GlaxoSmithKline Research and Development, Research Triangle Park, N.C.

e-mail: sreekumar.g.pillai@gsk.com

2. McCloskey, S. et al. Am. J. Respir. Crit. Care Med. 164, 1419-1424 (2001)

3. Ganrot, P. et al. Scand. J. Clin. Lab. Invest. 19, 205-208 (1967)

4. Thorgeirsson, T. et al. Nature 452, 638-642 (2008)

5. Wilk, J. et al. PLoS Genet. 5, e1000429; published online March 20, 2009; doi:10.1371/journal.pgen.1000429

\section{COMPANIES AND INSTITUTIONS MENTIONED}

Chiesi Farmaceutici S.p.A., Parma, Italy

Duke University, Durham, N.C.

GlaxoSmithKline plc (LSE:GSK; NYSE:GSK), London, U.K. Osaka City University Graduate School of Medicine, Osaka, Japan The University of Nottingham, Nottingham, U.K. 